\title{
O uso de Mandacaru (Cereus jamacaru) na alimentação de bovinos no interior do Piauí
}

\author{
Naiana Rosa da Silva ${ }^{1}$, Andreia Araújo de Almeida $^{1}$, Aparecida Maria Simões Mimura ${ }^{1 *}$
}

RESUMO: O município de São Raimundo Nonato (PI), localizado no Semiárido do Nordeste brasileiro, tem sofrido ao longo dos anos com a seca e a escassez de água. Assim, os pequenos criadores de gado buscam alternativas a esse problema, como a utilização do mandacaru (Cereus jamacaru DC, Cactaceae) na alimentação de seus rebanhos. Neste contexto, o objetivo deste trabalho foi verificar a importância do mandacaru na alimentação bovina no período de estiagem. Foram feitas entrevistas com 16 agricultores da zona rural de São Raimundo Nonato, nas comunidades Queimadinha, Veados, Garrincha e Nova Garrincha. Segundo a pesquisa realizada, 93,8\% dos entrevistados afirmaram que utilizam o mandacaru na alimentação do gado, seja puro ou misturado com outras forrageiras. Posteriormente foi investigado o teor de água no mandacaru, cujo valor encontrado foi em torno de $90 \%$ (estação chuvosa) e de $70 \%$ (estação seca), o que contribui para a hidratação dos animais, já que os agricultores buscam nesse tipo de vegetação uma alternativa para amenizar as dificuldades enfrentadas. Com a realização deste trabalho foi possível compreender a cultura regional e as práticas rurais, aproximando assim o conhecimento científico às tradições da população local.

Palavras-chave: Cereus jamacaru, seca, caatinga, forrageiras, bovinocultura.

\section{The use of Mandacaru (Cereus jamacaru) in cattle feed in the interior of Piauí}

\begin{abstract}
The city of São Raimundo Nonato (PI), located in the semiarid region of Northeastern Brazil, has suffered over the years with dry seasons and water scarcity. Thus, small cattle farmers are looking for alternatives to this problem, such as the use of mandacaru (Cereus jamacaru DC, Cactaceae) to feed their herds. In this context, the aim of this work was to verify the importance of mandacaru to feed the animals during dry season. Interviews were conducted with 16 farmers from rural communities of São Raimundo Nonato: Queimadinha, Veados, Garrincha and Nova Garrincha. According to them, $93.8 \%$ use mandacaru to feed cattle, either pure or mixed with other forages. Subsequently, the water content in mandacaru was investigated, founding the value around 90\% (wet season) and 70\% (dry season), which contributes to hydrate the animals, since farmers seek in this type of vegetation an alternative to ease the difficulties faced. Developing this work, it was possible to understand the regional culture and rural practices, approaching the scientific knowledge to the local popular traditions.
\end{abstract}

Keywords: Cereus jamacaru, dry season, caatinga, forages, herd of cattle.

\section{INTRODUÇÃOO}

O Semiárido brasileiro tem sofrido ao longo dos anos com a falta de chuva e a escassez de água (IBGE, 2019a). Dentre os municípios inclusos nessa região, pode-se citar o município de São Raimundo Nonato, localizado no Sul do Piauí, onde predomina o bioma da Caatinga. Os índices pluviométricos irregulares, com chuvas má distribuídas e longos períodos de seca têm influenciado decisivamente nas práticas rurais locais, como a agricultura e a pecuária (VIEIRA et al., 2005).

Desde que a agricultura começou a se estender nesta região, esta tem sido vulnerável às condições ambientais. Na Caatinga, a vegetação é composta basicamente por plantas que durante a estiagem perdem as suas folhagens. Os solos são cobertos por uma vegetação baixa, com plantas de pequeno porte e muito resistentes à seca, como por exemplo, as cactáceas (OLIVEIRA et al., 2007; SILVA, ALVES 2009).

Por ser um dos recursos naturais disponíveis no Semiárido brasileiro, as cactáceas possuem usos nas mais diversas áreas: alimentícia, medicinal, forrageira, ornamentação, bioindicador de chuva e conservação da biodiversidade, dentre outras (SILVA, 2015). No mundo todo existem cerca de 125 gêneros de cactáceas e 1.900 espécies, enquanto no Brasil, são conhecidas aproximadamente 160 espécies, pertencentes a 32 gêneros, sendo que na região Nordeste são encontrados 18 desses gêneros (ARRUDA et al., 2005).

Uma espécie de cactácea nativa da Caatinga que predomina a região de São Raimundo Nonato é o

Recebido em 30/03/2020; Aceito para publicação em: 11/09/2020

${ }^{1}$ Universidade Federal do Vale do São Francisco

*E-mail: aparecida.mimura@univasf.edu.br 
Cereus jamacaru DC. (Cactaceae), o mandacaru. O mandacaru é uma espécie endêmica do Brasil e sua área de distribuição natural se estende por diversos estados, como: Piauí, Pernambuco, Bahia, Rio Grande do Norte, Paraíba, Ceará, Sergipe, Alagoas, Goiás e, ainda, no norte de Minas Gerais (SILVA, ALVES, 2009). É uma planta com caule verde e provida de espinhos. Possui flores brancas, tronco grosso e ramificado, podendo medir de 3 a 7 metros de altura. Os frutos do mandacaru são vermelhos de polpa branca e suculenta, composto de muitas sementes pequenas de cor preta. Estes frutos têm caráter adocicado e podem ser consumidos tanto por animais quanto pelo homem. $\mathrm{O}$ mandacaru nasce em solos pedregosos e, juntamente a outras plantas, contribui para a formação da paisagem típica do Semiárido brasileiro (SALES et al., 2014; SILVA, ALVES, 2009). Costuma florescer a partir do mês de outubro, o que, segundo os agricultores e a cultura local, é um sinal de que a estação chuvosa está próxima à região (EMBRAPA, 2019).

No mandacaru, o órgão responsável pelo armazenamento de grande quantidade de água é o cladódio, que corresponde ao caule. As cactáceas, em geral, passaram por diversos processos morfológicos ao longo dos anos, a fim de se adaptarem às condições climáticas (SALES et al., 2014). As árvores normalmente perdem suas folhas em períodos secos, para evitar a perda de água através das mesmas. Durante o período de evolução, parte dos tecidos das folhas das cactáceas se atrofiou e as folhas se modificaram originando os espinhos. Além disso, as folhas são importantes para o processo de fotossíntese. No caso do mandacaru, a planta evoluiu para realizar a fotossíntese através do cladódio, que é verde (GODOFREDO, 2009). Assim, esses processos evolutivos, juntamente com a seleção natural, contribuíram para a adaptação fisiológica e morfológica do mandacaru.

Dessa forma, o mandacaru consegue resistir a longos períodos de seca, que geralmente ocorrem no Nordeste brasileiro, pois se adapta com facilidade a regiões com baixo índice pluviométrico e com poucos eventos de chuvas. As plantas dessa espécie possuem grande importância para os pequenos produtores rurais da região, pois podem servir como forrageira alternativa para a alimentação de bovinos, principalmente em períodos de estiagem (DAVET, 2005; REBOUÇAS, 2017).

$\mathrm{Na}$ agropecuária, para a suplementação alimentar dos animais podem ser usadas plantas forrageiras locais, com baixo custo, a fim de suprir as necessidades do rebanho e as deficiências das pastagens verdes nos períodos de seca, (JANUSCKIEWICZ et al., 2010; VIEIRA et al., 2005).
Do ponto de vista econômico, o uso do mandacaru na alimentação dos animais torna-se interessante, já que é encontrado com bastante facilidade nas regiões semiáridas, fazendo com que o pequeno produtor rural diminua as suas dificuldades com o cultivo de forrageiras (SALES et al., 2014). Neste contexto, o uso do mandacaru como forrageira, em períodos de estiagem, é uma prática simples que torna viável a produção animal no sertão brasileiro.

Uma das atividades tradicionais mais comuns na região de São Raimundo Nonato é a criação de animais, o que beneficia pequenos produtores rurais com produtos como leite, peles e carne. No entanto, as condições ambientais locais causam sérios prejuízos a esse setor. Assim, os pequenos criadores de gado dessa região tentam contornar esse problema, buscando forrageiras alternativas, como $o$ mandacaru, na alimentação de seus rebanhos durante os períodos de seca. Por isso, Cereus jamacaru DC. (Cactaceae) se configura como uma espécie muito importante para a sustentabilidade de práticas agropecuárias dessa região, compondo uma alternativa economicamente viável aos produtores, diminuindo os custos na criação dos animais. Além de ser uma fonte de alimentação barata, o mandacaru contribui também para a hidratação dos animais. Assim, se torna relevante o desenvolvimento de pesquisas envolvendo uma espécie nativa do Semiárido, a fim de ajudar na compreensão da importância dos recursos naturais da região.

Neste contexto, o objetivo deste trabalho foi verificar a importância do mandacaru para a alimentação do rebanho bovino no período de estiagem na região de São Raimundo Nonato, no interior do Piauí.

\section{MATERIAIS E MÉTODOS}

Este trabalho foi realizado na cidade de São Raimundo Nonato, localizada no sul do Piauí. O município possui aproximadamente 34.700 habitantes, divididos entre zona rural e zona urbana, de acordo com as estimativas do IBGE. A economia da cidade se baseia nos setores primários (agricultura e pecuária) e terciários (serviços) (IBGE, 2019b). Para a discussão do clima da região, dados meteorológicos contendo informações sobre a precipitação anual foram obtidos no Instituto Nacional de Meteorologia (INMET).

Foram realizadas entrevistas com agricultores e moradores da região de São Raimundo Nonato, nas comunidades localizadas na zona rural, tais como: Garrincha, Veados, Queimadinha, Nova Garrincha. Dentre os principais assuntos que foram abordados nessas entrevistas se destacam a possível utilização do mandacaru na alimentação do gado, a opinião da pessoa quanto a essa prática e a frequência de utilização do mandacaru. Os resultados das 
entrevistas foram discutidos na forma de textos, gráficos e utilizando ferramentas estatísticas, para verificar a porcentagem e a frequência das respostas. Logo após a entrevista, a convite de um agricultor foi possível observar o processo de alimentação de sua criação bovina, acompanhando todas as etapas, desde o corte do mandacaru até o momento em que este foi fornecido ao rebanho.

Para a determinação do teor de água, duas amostras de mandacaru, Cereus jamacaru DC. (Cactaceae), foram coletadas na zona rural de São Raimundo Nonato: a primeira em fevereiro e a segunda em setembro de 2019. Cada amostra media $30 \mathrm{~cm}$ de comprimento e $10 \mathrm{~cm}$ de diâmetro, aproximadamente. As amostras foram cortadas utilizando um facão a partir de um pé de mandacaru que media em torno de $3 \mathrm{~m}$ de altura. Após o corte, as amostras foram embaladas em um saco plástico e levadas ao laboratório, onde foram lavadas com água e depois fatiadas.

As massas das amostras foram obtidas usando uma balança digital semianalítica (marca Marte), antes e após a secagem. A secagem foi feita em uma estufa com circulação de ar (marca EDUTEC) a $80^{\circ} \mathrm{C}$, durante 24 horas. Para obter a massa de água contida no mandacaru, a massa da amostra seca foi subtraída da massa da amostra in natura.

\section{RESULTADOS E DISCUSSÃO}

Tabela 1. Precipitação anual em 2019, em mm, em algumas cidades brasileiras.

\begin{tabular}{ccc}
\hline Região & Cidade - Estado & Precipitação (mm) \\
\hline Nordeste & São Raimundo Nonato - PI & 19 \\
Nordeste & Salvador - BA & 1857 \\
Norte & Manaus - AM & 2261 \\
Centro-Oeste & Brasília - DF & 1365 \\
Sudeste & São Paulo - SP & 1694 \\
Sul & Porto Alegre - RS & 1529 \\
\hline
\end{tabular}

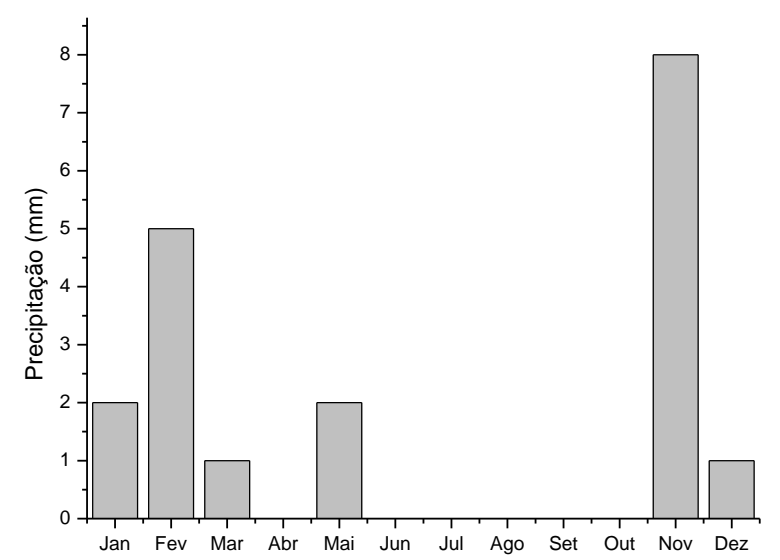

Figura 1 - Precipitação em São Raimundo Nonato, em 2019.

Para verificar o uso do mandacaru para a alimentação do gado, foram feitas entrevistas com 16 agricultores das comunidades da zona rural de São Raimundo Nonato. Foram entrevistados 11 homens e
Em São Raimundo Nonato, o clima é caracterizado por baixos índices pluviométricos, com pequeno volume de chuva ao longo no ano, com destaque para o período de julho a outubro, no qual é comum o quadro de seca extrema. Em geral, no sul do Piauí, a precipitação anual é abaixo de $600 \mathrm{~mm}$, fato observado em 2018 em São Raimundo Nonato (565 $\mathrm{mm}$ de chuva), segundo dados do INMET (2020). No entanto, em 2019, os índices pluviométricos foram extremamente baixos, totalizando apenas $19 \mathrm{~mm}$ de chuva neste ano. Conforme os dados obtidos pelo INMET (2020), este valor de precipitação anual é muito pequeno, comparado com o observado em outras cidades do Brasil em 2019 (Tabela 1).

De acordo com a Figura 1, não foi observada nenhuma precipitação nos meses de junho a outubro de 2019. Mesmo que tenha ocorrido alguma precipitação nesses meses, o volume de chuva foi tão pequeno que não pode ser detectado pelo INMET (2020). Dessa forma, nos meses onde a escassez de água é intensa em São Raimundo Nonato, o mandacaru se destaca como uma das poucas fontes de água e alimento disponíveis para o gado. Além do mandacaru, outras cactáceas como a palma (Opuntia ficus indica) e o xique-xique (Pilosocereus gounellei) também têm sido usadas no Nordeste brasileiro com este mesmo propósito (NETO et al., 2015). 
agricultores possuía entre 8 e 65 hectares, com uma média de 28 hectares.

Nestas propriedades, também havia diversos animais, cujas quantidades em média, por propriedade, foram: aves (45), bovinos (16), caprinos (98), colmeia (2), equinos (2) e suínos (7). Foi observado um número expressivo de caprinos e aves, muito maior do que o número de bovinos. Este fato pode estar relacionado ao alto valor aquisitivo de um animal como o boi, cujo valor comercial na região gira em torno de $\mathrm{R} \$ 1.500,00$. Tal valor é difícil de ser alcançado pela maioria dos agricultores da região de São Raimundo Nonato. Além disso, por causa do contexto local, o ecossistema apresenta pouca biomassa disponível, o que dificulta a alimentação de um animal de grande porte e grande demanda energética como o boi. Galinhas geralmente consomem folhas, insetos e frutas, dentre muitos outros alimentos de fácil acesso. Já os caprinos se alimentam preferencialmente de folhas de árvores, ervas e arbustos, e, em ambientes com vegetação escassa, modificam com facilidade seu consumo alimentar de acordo com a época do ano e disponibilidade das forrageiras (ROGÉRIO et al., 2016). Dessa forma, os caprinos e aves, além de terem valor comercial mais acessível, são animais de pequeno porte e que podem ser alimentados com mais facilidade em período de seca.

$\mathrm{Na}$ Figura 2, está apresentada a frequência de utilização do mandacaru para a alimentação do rebanho bovino em São Raimundo Nonato. Dentre os agricultores entrevistados, $37,5 \%$ afirmaram que sempre utilizam o mandacaru, enquanto $43,8 \%$ utilizam apenas durante o período de estiagem e $12,5 \%$ utilizam em épocas variadas dependendo da necessidade do rebanho. Dessa forma, somando estes percentuais, tem-se que 93,8\% dos agricultores entrevistados (15 agricultores dentre os 16 entrevistados) utilizam mandacaru na alimentação do rebanho bovino em alguma época do ano. De todos os entrevistados, somente 1 deles $(6,32 \%)$ afirmou que não tem o hábito de utilizar mandacaru em sua propriedade.

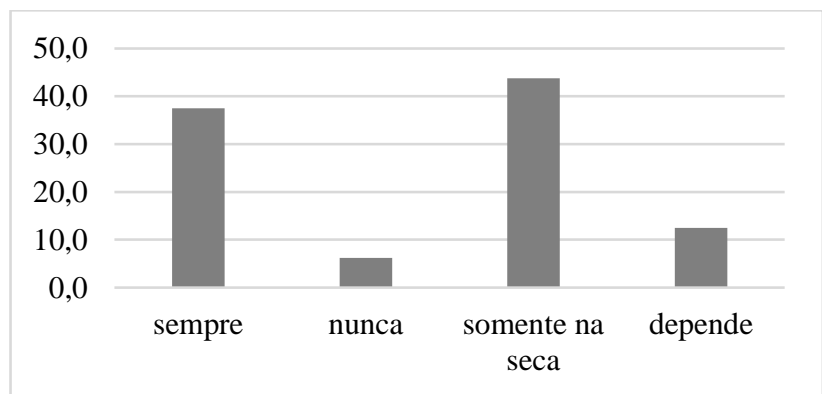

Figura 2 - Utilização do mandacaru na alimentação do rebanho bovino, expressa em porcentagem.

Estes dados indicam a importância da realização desse trabalho para a comunidade local. Para estes $93,8 \%$, o uso do mandacaru na alimentação do rebanho bovino é de fundamental importância, porque há períodos em que estes agricultores enfrentam grandes dificuldades devido à escassez de água e a falta de leguminosas para sua criação. Assim, de acordo com os agricultores de São Raimundo Nonato, o mandacaru é uma fonte bastante utilizada já que o semiárido disponibiliza este recurso. Tal relato também já foi observado em pesquisas feitas em outras localidades do Nordeste brasileiro, como Pernambuco e Paraíba, por exemplo (SILVA, 2015; NETO et al., 2015).

Mas, é necessário saber utilizá-lo de forma adequada, segundo relato dos agricultores. Por exemplo, não pode cortar a planta por inteiro, pois isto contribuiria para extinção desse vegetal. Portanto é importante cortar apenas os ramos para a alimentação do rebanho. A seguir, está apresentado um trecho da fala de um agricultor durante a entrevista na execução deste trabalho:
"O mandacaru é muito importante no período de seca, pois nos ajuda muito principalmente com a falta de alimentos na nossa região, já que nós não temos recursos financeiros para aguentar sustentar a criação apenas com ração. Por isso, não devemos sair por aí simplesmente cortando os pés de mandacaru porque, se acabarmos com eles, nos fará falta no futuro, não só pra gente como para as nossas gerações que também irão se remediar com esse tipo de vegetal".

\section{Um outro agricultor relata que:}

"Para nós é importante porque, já que não temos muito o que oferecer à criação, o mandacaru é uma planta de fácil acesso para nós".

Uma vez que grande parte dos agricultores entrevistados afirmaram o uso do mandacaru na alimentação do gado, o modo de uso foi investigado. 7 agricultores têm o hábito utilizá-lo de modo puro, enquanto os demais (8) afirmaram usar o mandacaru misturado com outros alimentos. A Figura 3 mostra 
alguns alimentos que são misturados com o mandacaru para a alimentação do rebanho bovino, conforme mencionado pelos entrevistados.

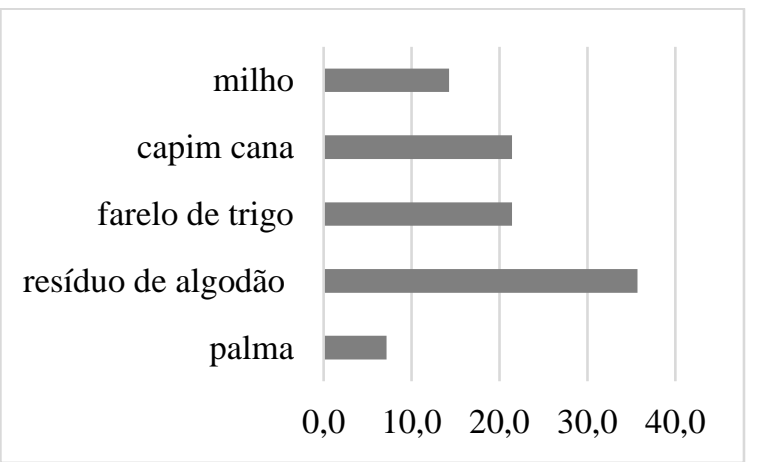

Figura 3 - Principais alimentos misturados com o mandacaru para a alimentação do rebanho bovino, expressos em porcentagem.

Dentre os alimentos, o resíduo de algodão se destacou, sendo utilizado por $35,7 \%$ dentre os 15 agricultores, seguido por farelo de trigo e capim cana $(21,4 \%)$, milho $(14,3 \%)$ e finalmente, palma $(7,1 \%)$.

O mandacaru, antes de ser oferecido ao rebanho pelos agricultores do município de São Raimundo Nonato, passa por um breve processo. Primeiramente, o mandacaru é tostado para a queima dos espinhos, a fim de não ferir a boca dos animais. Tal prática foi citada por todos os 15 entrevistados que usam o mandacaru na alimentação do gado. Em seguida, os agricultores têm o hábito de cortar e/ou triturar o mandacaru, facilitando assim a ingestão do alimento pelo rebanho. Vale destacar que não é comum produzir feno a partir do mandacaru, pois isso causaria perda de nutrientes e de água (CARVALHO et al., 2018).

Logo após a entrevista, a convite de um agricultor foi possível observar o processo de alimentação de sua criação bovina, acompanhando todas as etapas, desde o corte do mandacaru até o momento em que este foi ofertado ao rebanho. Primeiramente, o agricultor seleciona uma árvore qualquer, corta alguns galhos e acende uma fogueira. Em seguida, corta um galho do mandacaru, coloca o mesmo em um espeto e leva ao fogo para tostar os espinhos. $\mathrm{O}$ processo de tosta do mandacaru dura menos de $5 \mathrm{~min}$.
O mandacaru já tostado é deixado em repouso para resfriar, conforme também relatado por Carvalho et al. (2018). Depois de frio, é cortado em pedaços pequenos. Conforme já dito anteriormente, outros agricultores têm o hábito de triturar o mandacaru. Para verificar a quantidade de mandacaru oferecida ao rebanho no dia, uma pesagem foi feita em uma balança comercial, localizada em um pequeno mercado da comunidade Nova Garrincha. Foi possível alimentar duas vacas com aproximadamente $1.700 \mathrm{~g}$ de mandacaru, o que corresponde a 850 g/animal, diariamente. Dentre os 15 agricultores que afirmaram utilizar o mandacaru, 13 disseram que alimentam o gado uma vez por dia, normalmente ao final da tarde, depois que o animal já pastou livremente o dia todo. Por outro lado, 2 agricultores afirmaram que alimentam o gado 2 vezes por dia, de manhã e à tarde.

Para obter o teor de água do mandacaru, as amostras levadas ao laboratório, passaram por um processo de secagem na estufa, conforme descrito anteriormente. A massa da amostra foi obtida antes e após a secagem. A diferença entre essas massas corresponde à massa de água contida no mandacaru. $\mathrm{Na}$ Tabela 2 estão apresentados os resultados, em termos de porcentagem.

Tabela 2. Teor de água no mandacaru.

\begin{tabular}{ccc}
\hline & Matéria seca & Teor de água \\
\hline Amostra 1 & $9,72 \%$ & $90,3 \%$ \\
Amostra 2 & $28,1 \%$ & $71,9 \%$ \\
\hline
\end{tabular}

Analisando a amostra 1 de mandacaru obtida no mês de fevereiro (estação chuvosa), foi possível obter um teor de água de 90,28\%, o que corresponde a uma matéria seca de 9,72\%. Já a amostra 2, coletada no mês de setembro (estação seca), apresentou menor teor de água, 71,9\%. Mesmo em situações extremas de calor e seca extrema, o mandacaru apresentou um valor elevado de água em sua composição. Conforme relatado por Carvalho et al. (2018), o mandacaru apresenta, em média, $218 \mathrm{~g} \mathrm{~kg}^{-1}$ de matéria seca, o que corresponde a $21,8 \%$ de matéria seca e $78,2 \%$ de teor de água em sua composição, sendo estes valores comparáveis aos dados encontrados neste trabalho.

Na região de São Raimundo Nonato, a seca causa diversos desafios ao setor da agricultura. Por isso, os agricultores usam o mandacaru como alternativa para 
suprir o déficit de forrageiras, por ser uma planta que se adapta com facilidade às condições climáticas (SALES et al., 2014). A partir do experimento realizado, foi possível comprovar que grande parte do mandacaru é composta por água. Isso torna essa planta bastante relevante para o setor agropecuário da região, uma vez que muitos dos agricultores locais não têm condições financeiras para cultivar ou estocar outros alimentos que venham suprir as necessidades de seus animais na seca. De acordo com alguns dos agricultores entrevistados, o consumo de água de um animal como o boi é em média de 30 a $40 \mathrm{~L} \mathrm{dia}^{-1}$ animal $^{-1}$. Segundo a EMBRAPA (2020), o consumo de água pode alcançar de 22 a $78 \mathrm{~L} \mathrm{dia}^{-1}$ animal $^{-1}$, para bovinos de corte, variando em função da massa corporal dos mesmos (até $250 \mathrm{~kg}$ a até $455 \mathrm{~kg}$, respectivamente). Já em relação ao bovino de leite, o consumo varia de 45 a $64 \mathrm{~L}_{\mathrm{dia}^{-1}}$ animal $^{-1}$, considerando o estágio em que a vaca/novilha se encontra (gestante, final da gestação, lactação) (EMBRAPA, 2020). Neste contexto, o elevado teor de água do mandacaru, que é uma planta forrageira local, pode contribuir para a hidratação dos animais, ajudando na sobrevivência dos mesmos durante a seca.

Assim, o mandacaru se destaca como um importante recurso na alimentação de bovinos no Piauí, sendo uma forrageira acessível e facilmente encontrada na Caatinga. Essa prática agropecuária tem sido empregada tradicionalmente no interior do estado, como também em outras localidades do Nordeste brasileiro, tais como Paraíba, Sergipe, Pernambuco (CARVALHO et al., 2018; SALES et al., 2014; SILVA, 2015; NETO et al., 2015).

\section{CONCLUSÕES}

Neste trabalho foi possível concluir a importância do mandacaru na alimentação de bovinos para os agricultores do município de São Raimundo Nonato, localizado no Semiárido do Piauí. Segundo a pesquisa realizada, 93,8\% dos entrevistados afirmaram que utilizam o mandacaru na alimentação do gado, seja puro ou misturado com outras forrageiras. Por se tratar de uma planta típica da Caatinga e que é encontrada com bastante facilidade pelos agricultores, é muito relevante o consumo do mandacaru pelos animais, já que esta espécie de cactácea apresentou um elevado teor de água em sua composição (aproximadamente $90 \%$ durante a estação chuvosa e $70 \%$ durante a estação seca). Tal fato contribui para a alimentação dos animais em períodos de estiagem, já que os agricultores buscam nesse tipo de vegetação uma alternativa para amenizar as dificuldades enfrentadas.

A partir deste trabalho, foi possível compreender os desafios enfrentados pelos agricultores rurais da região e comprovar que o uso do mandacaru como um alimento para o gado, além de ser uma prática tradicional, contribui para a reposição de água para os animais em períodos de estiagem.

\section{AGRADECIMENTO}

Os autores agradecem à UNIVASF e aos agricultores que contribuíram com a pesquisa.

\section{REFERÊNCIAS}

ARRUDA, E. et al. Anatomia dos órgãos vegetativos de Cactacea da caatinga pernambucana. Rev. Brasil. Bot., Alagoinha, v. 28, n. 3, p. 589-601, 2005.

CARVALHO, C. B. M. et al. Uso de cactáceas na alimentação animal e seu armazenamento após colheita. Arch. Zootec., Bom Jesus, v. 67, n. 259, p. 440-446, 2018.

DAVET, A. Estudo fitoquímico e biológico do cacto (Cereus jamacaru) de candolle, Cactaceae. 2005. $121 \mathrm{f}$. Dissertação (Mestrado em Ciências Farmacêuticas) Universidade Federal do Paraná, Paraná.

EMBRAPA.

Disponível

em: <http://www.agencia.cnptia.embrapa.br/gestor/bioma_caa tinga/arvore/CONT000g79856tg02wx5ok0wtedt39zqb40 3.html>. Acesso em: agosto de 2019.

EMBRAPA. Disponível em: < https://www.embrapa.br/busca-de-publicacoes//publicacao/971085/consumo-de-agua-na-producaoanimal>. Acesso em: agosto de 2020.

GODOFREDO, V. R. Ontogênese, função e evolução das traqueídes vasculares em Cactaceae, tendo como modelo o cacto colunar Pilosocereus Aurisetus (WERDEN.) BYLES \& G. D. ROWLEY. 2009. $103 \mathrm{f}$. Dissertação (Mestrado em Botânica) - Universidade de São Paulo, São Paulo.

IBGE. Instituto Brasileiro de Geografia e Estatística. Disponível em: <https://www.ibge.gov.br>. Acesso em: agosto de 2019 (a).

IBGE. Instituto Brasileiro de Geografia e Estatística. Disponível em: <https://cidades.ibge.gov.br/brasil/pi/saoraimundo-nonato/panorama>. Acesso em: agosto de 2019 (b).

INMET. Instituto Nacional de Meteorologia. Disponível em: <http://www.inmet.gov.br>. Acesso em: março de 2020 .

JANUSCKIEWICZ, E. R. et al. Massa e composição química de três forrageiras de inverno manejadas sob duas alturas de resíduo e pastejo rotacionado. ARS Veterinária, Jaboticabal, v. 26, n. 1, p. 047-052, 2010.

NETO, J. A. S. et al. Potencial das cactáceas como alternativa alimentar para ruminantes no semiárido. Nutritime Revista Eletrônica, Viçosa, v. 12, n. 6, p. 44264434, 2015. 
OLIVEIRA, F. M. N. et al. Caraterização físico-química das polpas dos ramos do mandacaru. Revista Caatinga, Campina Grande, v. 20, n. 4, p. 89-92, 2007.

REBOUÇAS, B. R. Cactodera cacti (Nematoda: Heteroderidae): ocorrência natural em mandacaru (Cereus jamacaru DC.) no Ceará e investigação de hospedeiras em cactáceas e hortaliças. 2017. 69 f. Monografia (Graduação em Agronomia). Universidade Federal do Ceará, Ceará.

ROGÉRIO, M. C. P. et al. Manejo alimentar de caprinos e ovinos nos trópicos. Vet. e Zootec. Sobral, v. 23, n. 3, p. 326-346, 2016.

SALES, M. S. L. et al. Cereus jamacaru de candolle (Cactaceae), o mandacaru do nordeste brasileiro. Ci. Biol. Saúde, Picos, v. 20, n. 2, p. 135-142, 2014.

SILVA, L. R.; ALVES, R. E. Caracterização físicoquímica de frutos de "mandacaru". Rev. Acad., Cienc. Agrár. Ambient., Fortaleza, v. 7, n. 2, p. 199-205, 2009.

SILVA, V. A. Diversidade de uso das cactáceas no nordeste do Brasil: Uma Revisão. Gaia Scientia, Serra Talhada, v. 9, n. 2, p. 137-154, 2015.

VIEIRA, E. L. et al. Composição química de forrageiras e seletividade de bovinos em bosque-de-sabiá (Mimosa caesalpiniifolia Benth.) nos períodos chuvosos e seco. R. Bras. Zootec., Itambé, v. 34, n. 5, p.1505-1511, 2005. 